\title{
Aclidinium bromide inhibits human glioma cell proliferation, migration and invasion and promotes apoptosis via the PI3K/AKT signaling pathway
}

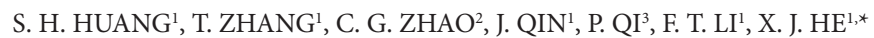 \\ ${ }^{1}$ Department of Orthopedics, The Second Affiliated Hospital, School of Medicine, Xian Jiaotong University, Xian, China; ${ }^{2}$ Xijing Hospital, Fourth \\ Military Medical University, Xian, China; ${ }^{3}$ Tangdu Hospital, Medical University of the Air Force, Xian, China
}

${ }^{*}$ Correspondence: hermit0105@163.com

Received November 3, 2017 / Accepted March 15, 2018

\begin{abstract}
This study investigates the anti-cancer potential of Aclidinium bromide (INN) in glioblastoma. Glioblastoma cell lines U251 and U87 were treated with INN and its effects on cell migration and invasion were assessed by transwell migration and invasion assays., The effects of INN on proliferation and apoptosis were detected by CCK- 8 kit and flow cytometry, and Western blotting determined anti-apoptotic proteins and signaling pathway changes. The results show that INN effectively suppressed proliferation, migration and invasion and induced apoptosis in U251 and U87 cells, respectively. Furthermore, the expression levels of the Bcl-2 anti-apoptotic protein was significantly decreased while Bax and caspase- 3 expression were both increased in glioblastoma cells (all, $\mathrm{p}<0.05$ ). Moreover, INN inactivated the PI3K/AKT signaling pathway by downregulating the level of p-AKT, p-mTOR, P70 and CyclinD1 (all, p<0.05). In conclusion, our data suggests that INN could provide novel anticancer therapy in the treatment of glioblastoma.
\end{abstract}

Key words: aclidinium bromide, glioblastoma, proliferation, migration, invasion, apoptosis

Glioblastoma is the most common malignant and aggressive form of brain cancer in the central nervous system and it accounts for $15-20 \%$ of all primary intracranial tumors [1, 2]. Glioblastoma is a complex and heterogeneous disease at the genetic and epigenetic levels [3] and has strong therapy resistance, high recurrence, and rapid progression [4] leading to high morbidity and mortality. Although recent treatment of glioblastoma and surgical methods and equipment have improved [5] patients, particularly those in advanced clinical stages, usually have high relapse rates and poor prognosis with survival rate less than $10 \%$ [4]. Therefore, in order to improve the survival of patients with glioblastoma, it is urgent to understand the molecular mechanism of glioblastoma progression and to develop new therapeutic strategies.

Aclidinium bromide (INN) is a new inhaled long-acting muscarinic antagonist (LAMA) which was approved by the European Medicines Agency and the US Food and Drug Administration on July 24, 2012 [6]. As a maintenance treatment for chronic obstructive pulmonary disease (COPD), INN has high affinity for all 5 human muscarinic receptor subtypes (M1-M5) and lower potential for anticholinergic adverse events [7]. In addition, INN can be rapidly hydro- lyzed to two major inactive metabolites in human plasma [8], and urinary excretion of the drug is therefore very low [9]. Although evidence confirms that INN can improve the life quality of patients with COPD [7], the functional role of INN in treatment of human glioblastoma still remains unknown.

This study applies INN to human glioblastoma U251 and U87 cells and determines its anti-tumor properties.

\section{Materials and methods}

Cell culture. Human glioblastoma cell lines U251 and U87 purchased from the Shanghai Academy of Sciences Cell Bank and the primary cultured HT22 cell line were cultured at $37^{\circ} \mathrm{C}$ and $5 \% \mathrm{CO}_{2}$ in DMEM-F12 media with $10 \%$ fetal bovine serum (FBS), penicillin (100 units/ml) and streptomycin $(0.1 \mathrm{mg} / \mathrm{ml})$. In the logarithmic phase, the cells were washed three times in PBS and then digested with trypsin enzyme. Medium was then added to terminate digestion and single cell suspension was planted in six orifice plates. Cell density reached $80 \%$ and the cells were exposed to INN (20 mM) for 24 hours. Negative controls were performed in DMSO (1:1000) diluted in medium. 
Western blot. Proteins from U251 and U87 cells following treatment with INN or DMSO at the above-mentioned concentrations for 24 hours were extracted by RIPA buffer. Protein concentration was determined by BCA method. Proteins were then separated in sodium dodecyl sulfate polyacrylamide electrophoresis (SDS-PAGE) gel and blotted onto a polyvinylidene difluoride membrane (PVDF). Membranes were blocked with $5 \%$ skim milk powder for 1 hour, followed by overnight incubation at $4 \mathrm{C}$ with indicated antibodies. Membranes were rinsed with TBST and then incubated with secondary antibodies for 1 hour at room temperature. GAPDH was used as an internal control and ECL kit was performed for chemiluminescent detection. Experiments were repeated at least three times.

Cell proliferation assays. Cell proliferation was evaluated by the CCK- 8 kit according to the manufacturer's protocol. The routine cultured cells were digested and counted and cell suspensions were plated at a density of 1,000 cells/well in 96-well culture plates and cultured with INN $(20 \mathrm{mM})$ in a $5 \% \mathrm{CO}_{2}$ incubator. Every $24 \mathrm{~h}, 10 \mu \mathrm{l} \mathrm{CCK8}$ medium was added to the plates for $1.5 \mathrm{~h}$ at $37^{\circ} \mathrm{C}$. The optical density (OD) was measured at $450 \mathrm{~nm}$ by ELISA reader and all experiments were performed in triplicate.
Transwell migration and invasion assay. To assess invasion ability, the upper chamber of 24 -well polycarbonate membrane transwell chambers were coated with matrigel (1:6; diluted with serum-free DMEM). After standing at $37^{\circ} \mathrm{C}$ for $4-6$ hours, $500 \mu \mathrm{l}$ serum-free medium was added to the lower chambers. $100 \mu \mathrm{l}$ suspension containing $1 \times 10^{5}$ cells treated with INN for 24 hours was then added to the upper chamber and $500 \mu \mathrm{l}$ Dulbecco modified eagle medium (DMEM) containing 10\% FBS was added to the lower chamber. After overnight incubation, cells that failed to pass through the membrane were removed with cotton-tipped swabs, and cells migrated to the lower membrane surface were immobilized with $4 \%$ methanol for $30 \mathrm{~min}$ and stained with $0.1 \%$ crystal violet solution for $10 \mathrm{~min}$. Five fields were randomly selected and quantified by microscopy. Similar to the invasive experiment, the transwell chamber in the migration test did not need to be treated with glue. The suspension contained $5 \times 10^{4}$ cells.

Apoptosis analysis. Cell apoptosis was analyzed by Annexin-V FITC staining. Briefly, U251 and U87 cells were seeded in 6-well plates and treated $24 \mathrm{~h}$ later with INN. After incubation of starvation condition for $24 \mathrm{~h}$, the cells were harvested, trypsinized, washed with cold PBS at

b

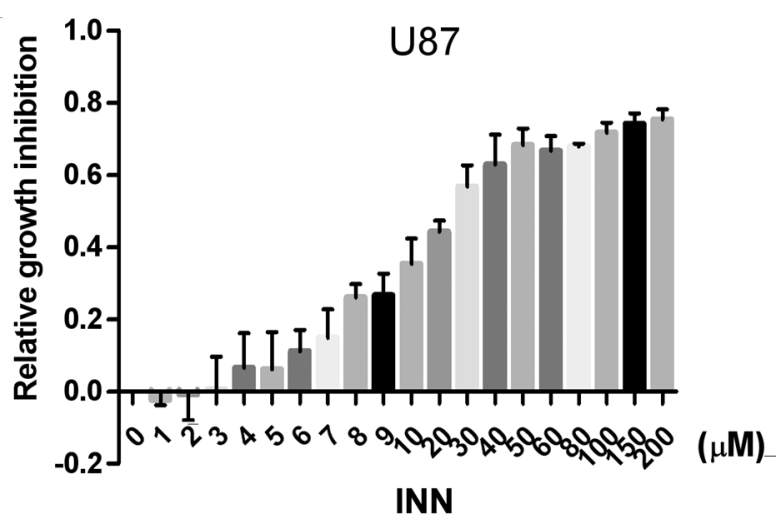

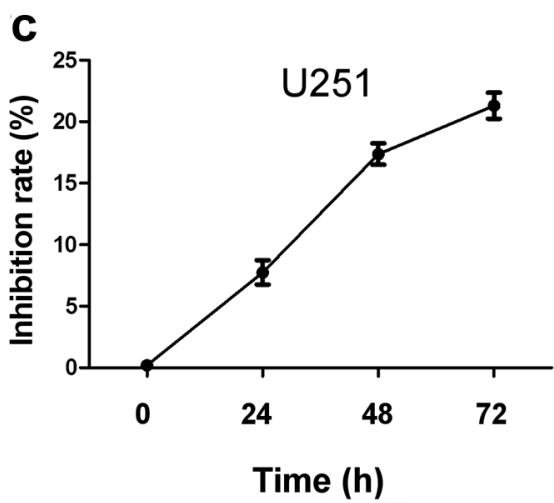
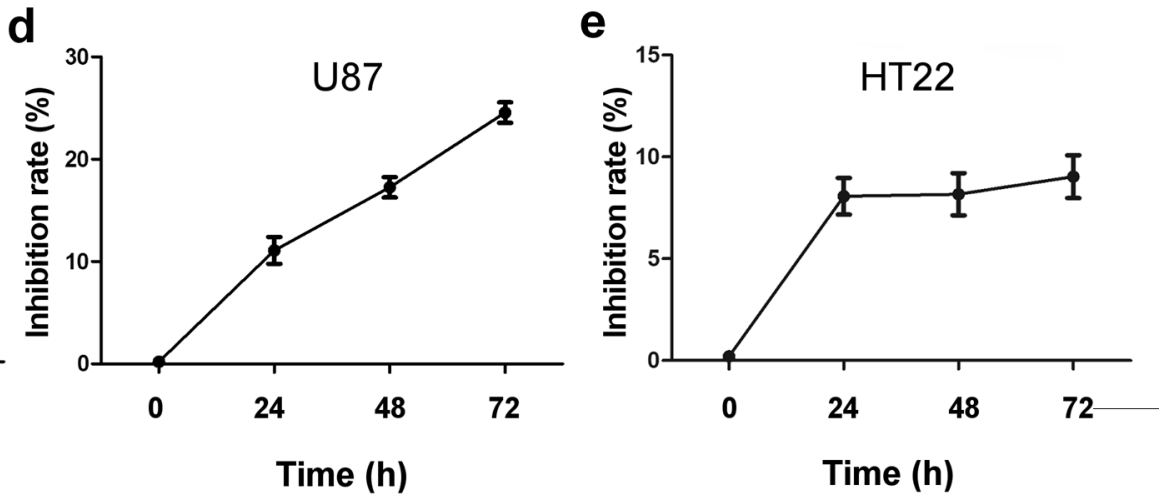

Figure 1. INN inhibits glioma cell proliferation. U251 (a), U87 (b) cells were treated with increasing concentrations of INN for 96 h. Both cell lines (c, d) as well as HT22 (e) cells were assessed for growth inhibition with $20 \mathrm{mM}$ INN using CCK-8 assay at $24 \mathrm{~h}, 48 \mathrm{~h}$, and $72 \mathrm{~h}$. 
$4{ }^{\circ} \mathrm{C}$ and centrifuged at room temperature. The cells were then re-suspended in Binding Buffer $1 \mathrm{X}$ and stained with Annexin-V FITC and PI for $10 \mathrm{~min}$ in the dark at room temperature. The samples were analyzed by Flowjo.

Statistical analysis. Statistical analyses were performed with SPSS 18.0 software (SPSS, Inc., Chicago, IL, USA), and data is expressed as mean \pm standard deviation (SD). Differences between two groups were determined by $t$ test, and $\mathrm{p}<0.05$ was considered statistically significant.

\section{Results}

INN reduced proliferation of U251 and U87 cells. In order to investigate the disease-resistant activity of INN, we evaluated the effects of INN on cell growth of U251 and U87 cell lines after $24 \mathrm{~h}, 48 \mathrm{~h}$ and $72 \mathrm{~h}$ by CCK- 8 . As shown in Figures $1 \mathrm{~A}$ and 1B, INN inhibited the growth of human U251 and U87 cells in a dose dependent manner at 96 hours, and the IC50 values in U251 and U87 cells were 18 and $20 \mathrm{mM}$, respectively. Therefore, INN at a final concentration of $20 \mathrm{mM}$ was collected for subsequent experiments. The effect of INN on cell proliferation indicated that INN is cytotoxic to U251 and U87 cells and inhibits cell proliferation in vitro at $24 \mathrm{~h}, 48 \mathrm{~h}$ and $72 \mathrm{~h}$ (Figures $1 \mathrm{C}$ and D).
To explore the effect of the concentration of $20 \mathrm{mM}$ INN on normal cells, we assessed the proliferation ability of HT22. The result showed that the concentration of INN had no significant effect on the proliferation of normal cells (Figure 1C).

INN inhibited migration and invasion of U251 and U87 glioblastoma cells. To further demonstrate the potential roles of INN on U251 and U87 cell migration and invasion, we performed transwell assays. The results showed that the INN-treated cell number passing the membrane was significantly lower than that of the control group in U251 and U87 cells (both $\mathrm{p}<0.01$; Figures $2 \mathrm{~A}, \mathrm{~B}$ ). Similarly, the invasion assay revealed that the invasive ability of U251 and U87 cells treated with INN was significantly decreased compared to controls (both, $\mathrm{p}<0.01$ ). The combined data suggests that INN is involved in the migration and invasion of glioblastoma cells, and treatment by INN inhibits glioblastoma cell migration and invasion.

Effect of INN on glioblastoma cell apoptosis. Subsequently, we investigated whether the INN was related to induction of glioblastoma apoptosis, and the number of apoptotic cells was assessed by the Annexin V-FITC/PI as described above. Figure $3 \mathrm{~A}$ shows that the percentage of apoptotic U251 cells treated with INN increased compared

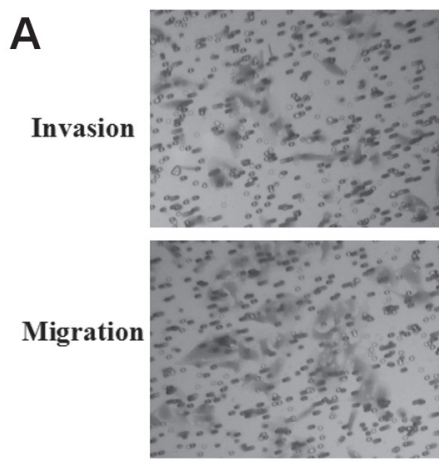

NC

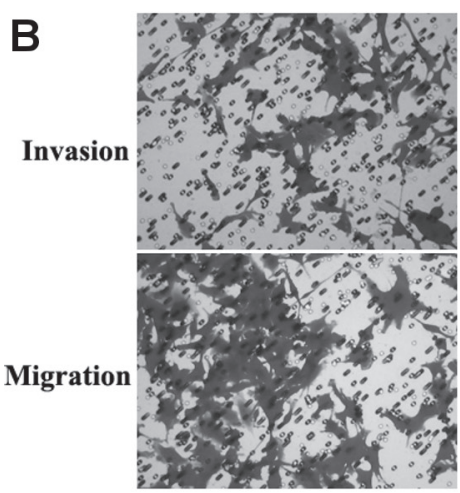

NC

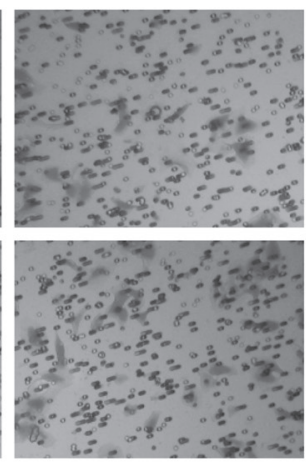

Aclidinium

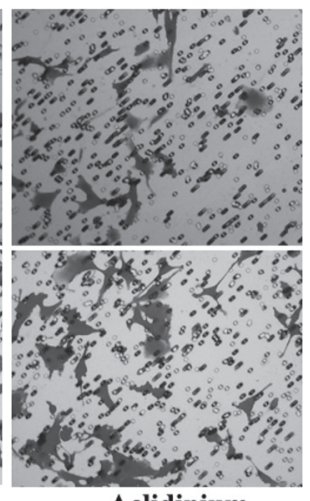

Aclidinium
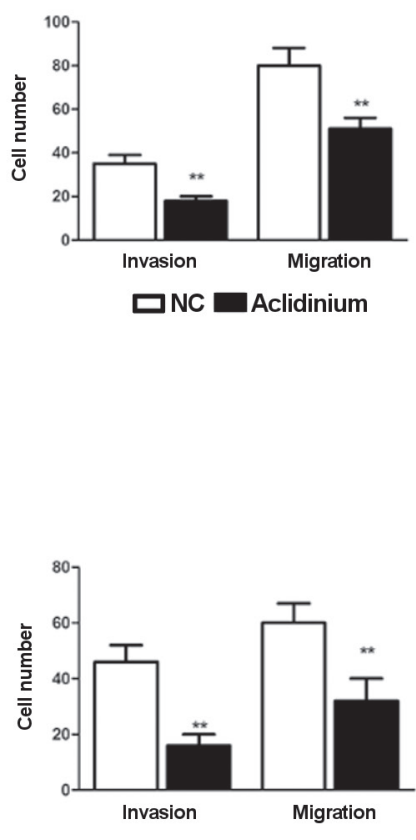

$\square$ NC $\square$ Aclidinium

Figure 2. Transwell migration and invasion assay. INN inhibits U251 (A) and U87 (B) cells migration and invasion compared to the controls. ${ }^{\star *}$ p $<0.01$. 
to control cells $(23.78 \%$ versus $5.69 \%)$. Similarly, treatment with INN significantly induced apoptotic response in U87 cells compared to controls (27.80\% versus $13.16 \%$; Figure $3 \mathrm{~B}$ ). Furthermore, in order to further confirm the apoptotic effect induced by INN, we also tested Bcl2/Bax and caspase- 3 proteins related to apoptosis. Western blotting analysis demonstrated that INN treatment decreased the expressions of $\mathrm{Bcl}-2$, but increased the expression of Bax and caspase- 3 in U251 and U87 cells (Figures 3C, D - all $\mathrm{p}<0.05$ ). Collectively, INN induced apoptosis of glioblastoma cells by regulating the expression of apoptosis-related proteins.
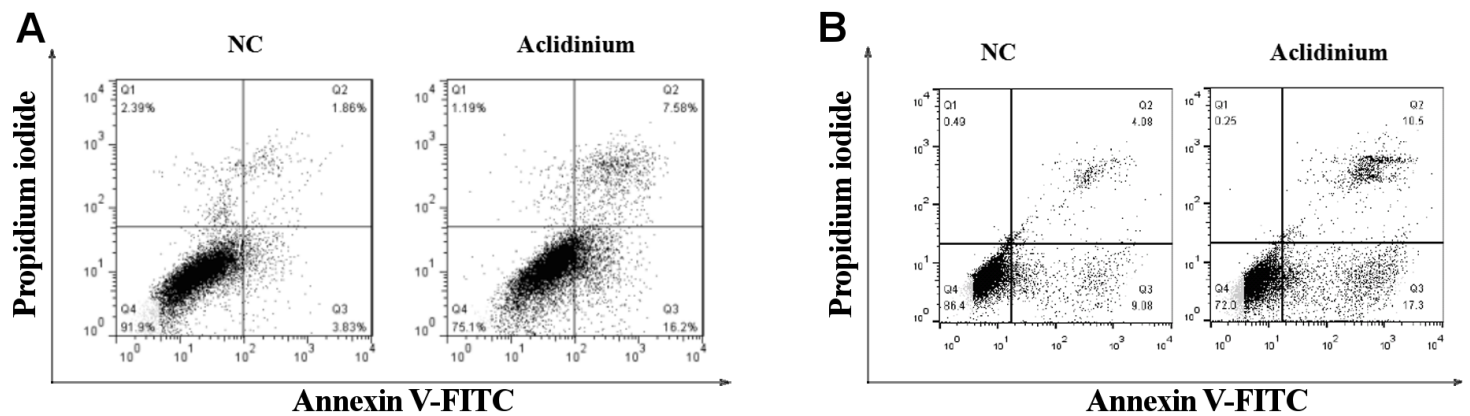

\section{C}
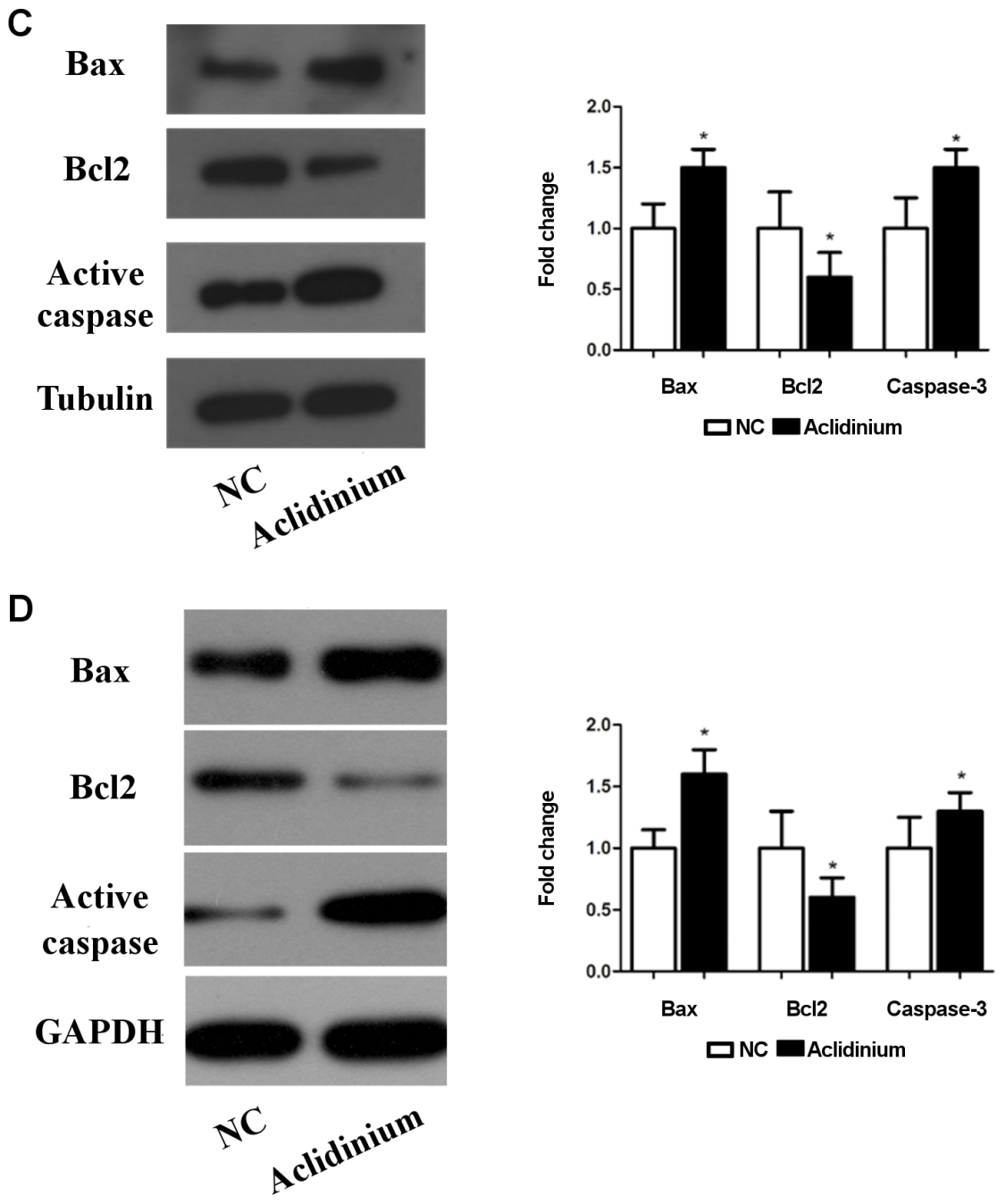

Figure 3. Effects of INN on cell apoptosis in glioblastoma cells. Effect of INN on U251 (A) and U87 (B) cell lines apoptosis detected by flow cytometry. The protein levels Bcl-2, Bax and caspase-3 of detecting using western blotting on U251 (C) and U87 (D) cell lines. ${ }^{*}$ p $<0.05$. 
INN inhibited the activation of the PI3K/AKT signal pathway of glioblastoma cells. Previous studies showed that the PI3K signaling pathway was involved in tumor progression with essential AKT and mTOR proteins, and that this has important roles in tumor cell proliferation and metastasis. Based on this knowledge, we speculated that INN regulated glioblastoma through the PI3K/AKT signal pathway. As shown in Figure $4 \mathrm{~A}$ and $4 \mathrm{~B}$, INN treatment significantly down-regulated the level of p-AKT and p-mTOR (both, $\mathrm{p}<0.05)$ in U251 and U87cell lines. More importantly, the down-stream proteins of P70 and CyclinD1 were significantly decreased in cells treated with INN compared to controls.

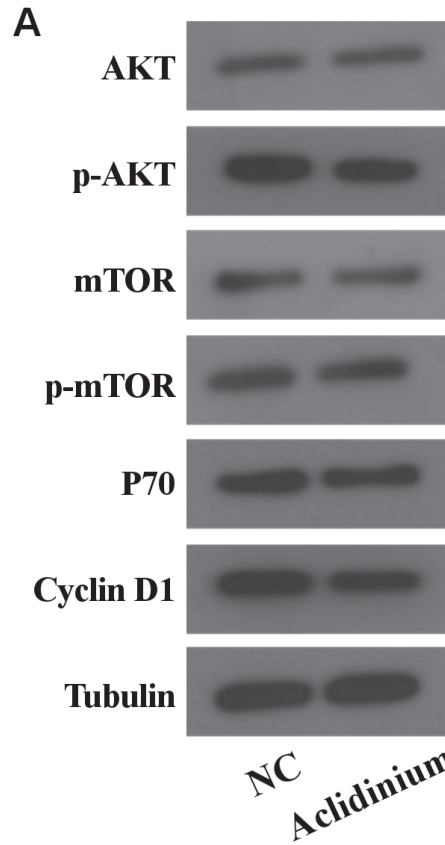

B
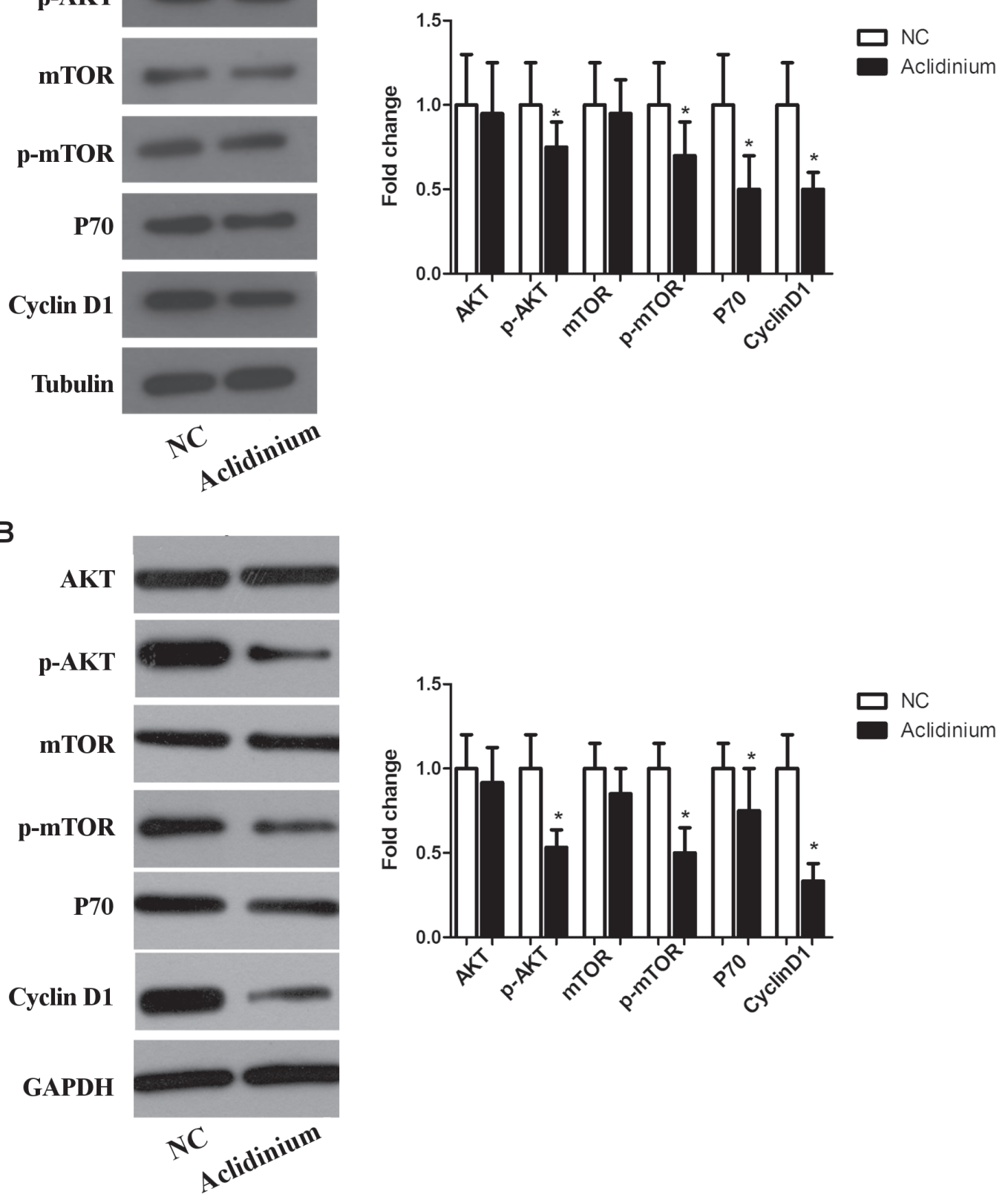

Figure 4. INN negatively regulates PI3K/AKT signaling pathway. The expression of AKT, p-AKT, mTOR, p-mTOR, P70 and Cyclin D1 were detected by western blotting on $\mathrm{U} 251$ (A) and U87 (B) cell lines. ${ }^{*} \mathrm{p}<0.05$. 
Generally, the results suggest that INN inhibits glioblastoma progression by deregulating the PI3K/AKT signal pathway.

\section{Discussion}

As commonly found in intracranial tumors with relatively high rates of recurrence, glioblastoma has poor response to conventional surgery, radiotherapy, chemotherapy and targeted therapy, and produces profound side effects. Although more and more anti-tumor drugs have been investigated, most are expensive and have adverse reactions. More importantly, most are restricted in clinical application [10-14]. Therefore, it would be helpful to discover new drugs with low toxicity, efficacy and stability for the treatment of glioblastoma. In this study, for the first time, we found that INN could inhibit glioblastoma cell migration and invasion and promote their apoptosis. Moreover, we also demonstrated that INN was able to inactivate the PI3K signaling pathway.

While INN has been a valuable new therapy in the treatment of COPD, this is the first investigation of its glioblastoma anti-tumor effects. Abnormal cell proliferation is a major factor in the development of tumors, and therefore the inhibition of cell proliferation could be an effective antitumor therapy. Although dose-dependent INN can reduce fibroblast proliferation [15], there have been only a few reports in glioblastoma cells, but this study confirms that INN significantly inhibited cell proliferation in U251 and U87 cells.

Previous studies have shown that migration and invasion are the main biological characteristics related to tumor malignancy, including in glioblastoma [16-18]. Moreover, they are complex processes and major contributors to poor prognosis. Alagha et al [19] revealed that some LAMAs showed anti-inflammatory effects in inhibiting the migration of alveolar neutrophils.

In accordance with previous studies of INN in COPD, our data demonstrated that INN has an inhibitory effect on the migration and invasion of U251 and U87 glioma cells. The combined results indicate that INN inhibits the development of glioblastoma by inhibiting glioma cell migration and invasion.

Research demonstrates that there are lots of factors leading to apoptosis in cells, and anti-tumor drugs are one of the external factors [20]. According to our study, the results revealed INN could induce apoptosis, decrease expression of $\mathrm{Bcl}-2$, and increase expression of Bax and caspase-3. Bcl-2, Bax and caspase- 3 are apoptosis-related genes which have important roles in the regulation of apoptosis. As important members of the Bcl-2 protein family, Bcl-2 and Bax are important factors in the intrinsic apoptotic pathway [21, $22]$. The $\mathrm{Bcl}-2$ protein, in particular, inhibits cell apoptosis through multiple mechanisms [23] and caspase-3 is also an essential terminal caspase in apoptosis execution [21].

Accumulating evidence demonstrates that the PI3K/AKT pathway is a crucial signaling pathway in cancer development
[24-27], and this is significantly activated in glioma [28, 29]. In glioma, the PI3K/AKT signaling pathway plays a crucial role in the induction of proliferation, migration and invasiveness [30]. Therefore, inhibition of PI3K/AKT signaling presents a potential approach for anti-tumor therapy. In this study, we assessed the effects of INN on the PI3K/AKT signaling pathway to further explore the molecular mechanisms INN employs to inhibit the proliferation, invasion and migration of U251 and U87 cells. The results indicated that INN reduces the level of $\mathrm{p}-\mathrm{AKT}$ and $\mathrm{p}$-mTOR. More importantly, the down-stream proteins of P70 and CyclinD1 were down-regulated after INN treatment. In fact, aberrant activation of Akt is frequently observed in glioma [31], and mTOR regulates multiple cell growth by controlling mRNA translation and metabolism [32]. Inhibition of mTOR therefore leads to regional apoptosis [33].

In conclusion, our research suggests that INN can inhibit proliferation, migration and invasion. INN can also promote apoptosis of human glioma cells via the PI3K/AKT signaling pathway, and it may therefore serve as a successful new anticancer drug in treating patients with glioma. While this is a distinct possibility, additional studies are still required to investigate INN's effects in vivo.

\section{References}

[1] LOUIS DN, PERRY A, REIFENBERGER G, VON DEIMLING A, FIGARELLA-BRANGER D et al. The 2016 World Health Organization Classification of Tumors of the Central Nervous System: a summary. Acta Neuropathol 2016; 131: 803-820. https://doi.org/10.1007/s00401-016-1545-1

[2] BHUVANALAKSHMI G, ARFUSO F, MILLWARD M, DHARMARAJAN A, WARRIER S. Secreted frizzled-related protein 4 inhibits glioma stem-like cells by reversing epithelial to mesenchymal transition, inducing apoptosis and decreasing cancer stem cell properties. PLoS One 2015; 10: e0127517. https://doi.org/10.1371/journal.pone.0127517

[3] REIFENBERGER G, WIRSCHING HG, KNOBBE-THOMSEN CB, WELLER M. Advances in the molecular genetics of gliomas - implications for classification and therapy. Nat Rev Clin Oncol 2017;14: 434-452. https://doi.org/10.1038/ nrclinonc.2016.204

[4] STUPP R, HEGI ME, MASON WP, VAN DEN BENT MJ, TAPHOORN MJ et al. Effects of radiotherapy with concomitant and adjuvant temozolomide versus radiotherapy alone on survival in glioblastoma in a randomised phase III study: 5-year analysis of the EORTC-NCIC trial. Lancet Oncology 2009; 10: 459-466. https://doi.org/10.1016/S14702045(09)70025-7

[5] LI WQ, LI YM, TAO BB, LU YC, HU GH et al. MicroRNA-328 may contribute to chemoresistance in glioblastoma cancer stem cells by targeting ABCG2. Med Sci Monit 2010; 16: HY27-HY30.

[6] GAVALDA A, RAMOS I, CARCASONA C, CALAMA $\mathrm{E}$, OTAL $\mathrm{R}$ et al. The in vitro and in vivo profile of aclidinium bromide in comparison with glycopyrronium bromide. Pulm Pharmacol Ther 2014; 28: 114-121. https://doi. org/10.1016/j.pupt.2014.05.005 
[7] GAVALDA A, MIRALPEIX M, RAMOS I, OTAL R, CARRENO $\mathrm{C}$ et al. Characterization of aclidinium bromide, a novel inhaled muscarinic antagonist, with long duration of action and a favorable pharmacological profile. J Pharmacol Exp Ther 2009; 331: 740-751. https://doi.org/10.1124/ jpet.109.151639

[8] GAVALDA A, GARCIA-GIL E. Aclidinium bromide, a novel long-acting muscarinic antagonist (LAMA). p 33-38. In: TT. Hansel, PJ. Barnes (Eds.), New Drugs and Targets for Asthma and COPD. Karger Basel, 2010, pp. 310. ISBN: 9783-8055-9566-7

[9] SCHMID K, PASCUAL S, GIL EG, ORTIZ S, JANSAT JM. Pharmacokinetics and safety of aclidinium bromide, a muscarinic antagonist, in adults with normal or impaired renal function: A phase I, open-label, single-dose clinical trial. Clin Ther 2010; 32: 1798-1812. https://doi.org/10.1016/j. clinthera.2010.09.002

[10] OKADA M, SATO A, SHIBUYA K, WATANABE E, SEINO $S$ et al. JNK contributes to temozolomide resistance of stem-like glioblastoma cells via regulation of MGMT expression. Int J Oncol 2014; 44: 591-599. https://doi.org/10.3892/ ijo.2013.2209

[11] ZHANG P, ZHOU Q, TIAN L, ZHOU X, ZHOU Y et al. Experimental study of a novel tumstatin on C6 brain glioma in vitro. Oncol Lett 2017; 14: 2845-2851. https://doi. org/10.3892/ol.2017.6507

[12] SZE CI, SU WP, CHIANG MF, LU CY, CHEN YA et al. Assessing Current Therapeutic Approaches to Decode Potential Resistance Mechanisms in Glioblastomas. Front Oncol 2013; 3: 59. https://doi.org/10.3389/fonc.2013.00059

[13] MAIMAITILI A, SHU Z, CHENG X, KAHEERMAN K, SIKANDEER A et al. Arctigenin, a natural lignan compound, induces G0/G1 cell cycle arrest and apoptosis in human glioma cells. Oncol Lett 2017; 13: 1007-1013. https://doi. org/10.3892/ol.2016.5474

[14] ZHENG J, DU W, SONG LJ, ZHANG R, SUN LG et al. Norcantharidin induces growth inhibition and apoptosis of glioma cells by blocking the Raf/MEK/ERK pathway. World J Surg Oncol 2014; 12: 207. https://doi.org/10.1186/14777819-12-207

[15] MILARA J, SERRANO A, PEIRO T, GAVALDA A, MIRALPEIX $M$ et al. Aclidinium inhibits human lung fibroblast to myofibroblast transition. Thorax 2012; 67: 229-237. https:// doi.org/10.1136/thoraxjnl-2011-200376

[16] GASSMANN P, ENNS A, HAIER J. Role of tumor cell adhesion and migration in organ-specific metastasis formation. Onkologie 2004; 27: 577-582. https://doi. org/10.1159/000081343

[17] ZHANG X, LV QL, HUANG YT, ZHANG LH, ZHOU HH. Akt/FoxM1 signaling pathway-mediated upregulation of MYBL2 promotes progression of human glioma. J Exp Clin Cancer Res 2017; 36: 105. https://doi.org/10.1186/s13046017-0573-6

[18] FENG L, MA J, JI H, LIU Y, HU W. miR-330-5p suppresses glioblastoma cell proliferation and invasiveness through targeting ITGA5. Biosci Rep 2017; 37. pii: BSR20170019. https://doi.org/10.1042/BSR20170019
[19] ALAGHA K, PALOT A, SOFALVI T, PAHUS L, GOUITAA $\mathrm{M}$ et al. Long-acting muscarinic receptor antagonists for the treatment of chronic airway diseases. Ther Adv Chronic Dis 2014; 5: 85-98. https://doi.org/10.1177/2040622313518227

[20] LI Y, LI Z. [Mitochondria and apoptosis]. Zhonghua Yu Fang Yi Xue Za Zhi 2000; 34: 183-184.

[21] FULDA S, DEBATIN KM. Targeting apoptosis pathways in cancer therapy. Current Cancer Drug Targets 2004;4:569-576.

[22] JIN Z, EL-DEIRY WS. Overview of cell death signaling pathways. Cancer Biol Ther 2005; 4: 139-163.

[23] HEATH-ENGEL HM, CHANG NC, SHORE GC. The endoplasmic reticulum in apoptosis and autophagy: role of the BCL-2 protein family. Oncogene 2008; 27: 6419-6433. https://doi.org/10.1038/onc.2008.309

[24] THAPA N, CHOI S, TAN X, WISE T, ANDERSON RA. Phosphatidylinositol Phosphate 5-Kinase I $\gamma$ and Phosphoinositide 3-Kinase/Akt Signaling Couple to Promote Oncogenic Growth. J Biol Chem 2015; 290: 18843-18854. https://doi.org/10.1074/jbc.M114.596742

[25] KE Z, CAIPING S, QING Z, XIAOJING W. Sonic hedgehogGlil signals promote epithelial-mesenchymal transition in ovarian cancer by mediating PI3K/AKT pathway. Med Oncol 2015; 32: 368. https://doi.org/10.1007/s12032-014-0368-y

[26] LUO Q, WANG C, JIN G, GU D, WANG N et al. LIFR functions as a metastasis suppressor in hepatocellular carcinoma by negatively regulating phosphoinositide 3-kinase/AKT pathway. Carcinogenesis 2015; 36: 1201-1212. https://doi. org/10.1093/carcin/bgv108

[27] COURTNEY KD, CORCORAN RB, ENGELMAN JA. The PI3K pathway as drug target in human cancer. J Clin Oncol 2010; 28: 1075-1083. https://doi.org/10.1200/ JCO.2009.25.3641

[28] KITA D, YONEKAWA Y, WELLER M, OHGAKI H. PIK3CA alterations in primary (de novo) and secondary glioblastomas. Acta Neuropathol 2007; 113: 295-302. https:// doi.org/10.1007/s00401-006-0186-1

[29] RAJASEKHAR VK, VIALE A, SOCCI ND, WIEDMANN $\mathrm{M}, \mathrm{HU} \mathrm{X}$ et al. Oncogenic Ras and Akt signaling contribute to glioblastoma formation by differential recruitment of existing mRNAs to polysomes. Mol Cell 2003; 12: 889-901.

[30] ZHANG X, SONG Q, WEI C, QU J. LRIG1 inhibits hypoxiainduced vasculogenic mimicry formation via suppression of the EGFR/PI3K/AKT pathway and epithelial-to-mesenchymal transition in human glioma SHG-44 cells. Cell Stress Chaperones 2015; 20: 631-641. https://doi.org/10.1007/ s12192-015-0587-y

[31] HOLLAND EC, CELESTINO J, DAI C, SCHAEFER L, SAWAYA RE et al. Combined activation of Ras and Akt in neural progenitors induces glioblastomaformation in mice. Nature Genetics, 2000; 25: 55-57. https://doi. org/10.1038/75596

[32] SHAW RJ, CANTLEY LC. Ras, PI(3)K and mTOR signaling controls tumor cell growth. Nature 2006; 441: 424-430. https://doi.org/10.1038/nature04869

[33] HU X, PANDOLFI PP, LI Y, KOUTCHER JA, ROSENBLUM M et al. mTOR Promotes Survival and Astrocytic Characteristics Induced by Pten/Akt Signaling in Glioblastoma. Neoplasia 2005; 7: 356-368. 